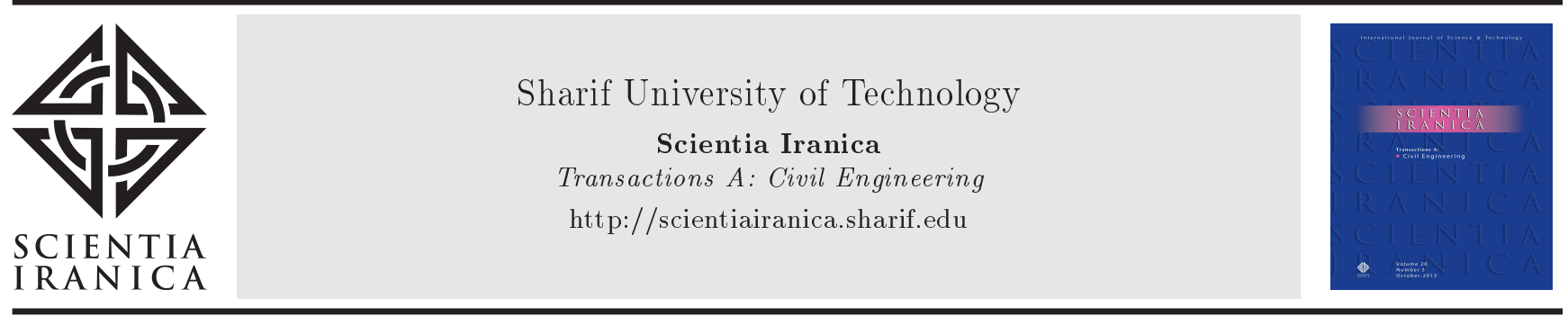

\title{
Exploring worker's absence pattern in the construction industry in Iran
}

\author{
A. Alvanchi* and A. Hashemi \\ Department of Civil Engineering, The Sharif University of Technology, Tehran, Iran.
}

Received 23 July 2018; received in revised form 17 January 2020; accepted 28 April 2020

\section{KEYWORDS}

Absence pattern; Absenteeism; Human resource management; Construction management; Iran.

\begin{abstract}
Workers' absence considerably affects the performance of labor-intensive construction projects. Identifying such absence patterns assists construction project managers in preparing proper project organization, reducing the absence rate, and improving the project performance. Despite its critical role, no study has investigated the absence pattern in the construction industry in Iran. This study addresses this gap by identifying the worker's absence pattern and providing recommendations to reduce the absence rate. First, a comprehensive literature review is conducted on the impacts of influential factors in the worker's absence. Then, a questionnaire-based survey is designed and distributed among project managers, work supervisors, and human resource experts in different construction companies. The absence rate of seven percent achieved for the construction industry in Iran is among the high rates compared to the rates reported for other countries. The organizational policies, the national holiday season, and the size of the working groups are among the main influential factors. Enhancing teamwork spirit, enforcing severe implications for the worker's absence, and increasing managers' site visits are among the recommended policies for reducing the absence rate. The identified pattern in this research applies to evaluating and improving the performance of construction companies in Iran.
\end{abstract}

(C) 2021 Sharif University of Technology. All rights reserved.

\section{Introduction}

Human Resource (HR) management is a challenging job in labor-intensive and dynamic construction projects. Various worker-related influential factors in the construction project productivity were identified in past research [1]. The worker's absence is one of the main influential factors frequently reported in

\footnotetext{
*. Corresponding author. Tel.: +9821 66164221; Fax: +982166014828

E-mail addresses: alvanchi@sharif.edu (A. Alvanchi); amir.hashemi@alumni.ut.ac.ir (A. Hashemi)
}

past research efforts (e.g. [2-5]). Compared to the planned vacation days, the worker's absence involves an unplanned element. The absence can happen due to 1) excusable reasons such as illness, injury, or bereavement or; 2) Non-excusable reasons such as attending a football match, going on a pleasure trip, or not feeling to work. Inexcusable absence is also called absenteeism [6].

Past investigations evaluated significant impacts of the worker's absence in the construction industry in multiple directions. The business roundtable [7] estimated that an absence rate of $10 \%$ could cause a $15 \%$ decline in the profitability of construction projects in the United States. Ferguson et al. [8] reported that the reduced safety level and the increased number of 
accidents were the two effects of a worker's absence. Hanna et al. [9] evaluated the negative impacts of the worker's absence on the productivity of construction projects by about $9 \%$. Nicholson et al. [10] found the median cost of a worker's absence to be 1.28 times the original wage in 35 different jobs in the United States. In this research, the cost of the construction engineer's absence was the highest. Sichani et al. [11] found work delay, increased overtime, increased cost, and reduced safety among direct and indirect impacts of the worker's absence in the construction projects. Strömberg et al. [12] estimated that the average cost of an absent construction worker was 2.17 times the wages in Sweden. Leaker [13] estimated a capital loss of 19.2 billion dollars in different industries in England as a result of worker's absence. In Belgium, Grinza and Rycx [14] found that $1.0 \%$ of the worker's absence resulted in a productivity loss of $0.24 \%$.

In Iran, construction is a major industry with a nearly $9 \%$ share in the country's Gross Domestic Product (GDP) [15]. Construction projects, however, suffer from high project delays and cost overruns in Iran [16-19]. The labor-intensive structure of construction projects in the country puts labor productivity forward as a key contributor [20,21]. Meanwhile, the worker's absence has been identified as an effective factor in the construction projects' labor productivity in Iran [22]. Identifying the worker's absence pattern and its influential factors in the country can assist construction managers in adjusting their policies to reduce the worker's absence and ultimately improve labor productivity. Many past research efforts have investigated the construction worker's absence pattern in different regions. Their achieved results, however, are not necessarily applicable to the specific condition of Iran since regional factors can affect this pattern. Country-specific characteristics were found the main contributors to the absence pattern in a research conducted by Langenhoff [23] for modeling the absence pattern in different European countries. Reported rates of construction the worker's absence represent a wide range in different countries. This rate is $2.8 \%$ in Europe for the average of all industries [24], 2.4\% in the United States [25], 8.4\% in Canada [26], 2.1\% in the United Kingdom [27], and 5.9\% in Lebanon (based on the weighted averaging of unskilled workers, skilled workers, and foremen) [28]. Nevertheless, research efforts that explore the worker's absence pattern in the specific condition of Iran are still missing.

Therefore, the current study was conducted to identify the absence pattern of and the main influential factors in the worker's absence in the construction industry in Iran. The identified pattern can be used for construction managers in the country to evaluate their standing, alleviate their negative impacts, and adjust their policies to address the influential factors.
First, influential factors in the worker's absence identified in the past research are reviewed. Then, different stages of the adopted survey-based method for extracting the worker's absence pattern in the construction industry in Iran are explained. Next, the survey questionnaire design and the questionnaire distribution results are presented. Subsequently, the extracted absence pattern is discussed and analyzed for the construction projects in Iran. Finally, the research outcome is concluded and recommendations are provided for future research efforts.

\section{Past research}

Significant impacts of the worker's absence on the construction project performance have encouraged researchers to investigate its influential factors. A review of the past research represents a wide range of influential factors in the worker's absence. These influential factors can be divided into two internal and external categories. The internal factors originate from the internal project sources which can be handled by the project manager. However, the external factors initiate from the sources out of the project manager's reach. Table 1 summarizes the identified influential factors from past research.

Identifying influential factors in the worker's absence aimed to guide construction project managers to adjust their organizational policies and prepare for alleviating the negative impacts of the worker's absence. Hanna et al. [9] studied absenteeism in electrical construction. Their recommended best practices for reducing absenteeism redefined the overtime condition using flexible schedules, improving safety, promoting an "open-door" policy for the managers, and publicly announcing workers' attendance. To reduce the worker's absence rate, Langenhoff [23] in Portugal recommended organizational managers to incorporate workers' absence control policy during the recruitment process, provide both part-time and full-time contract options, and allocate daycare centers. In the research conducted by Sichani et al. [11] in Canada, they found that the use of disciplinary actions for the worker's absence was effective when the employment rate was low in the country. They also found that announcing the job-sites average absence rate would be an effective strategy in reducing the worker's absence.

Biron and Bamberger [29] found frontline supervisor support and job training effective policies to minimize the worker's absence rate in a large municipality in the United States. Bhosale and Biswas [30] proposed remedial instructions to mitigate the worker's absence in construction projects in India. These instructions included adjusting personnel policies, providing proper medical check-ups, providing daily meals for the workers, setting organizational 
Table 1. Worker's absence identified influential factors in different research efforts.

\begin{tabular}{|c|c|c|}
\hline \multirow{19}{*}{ 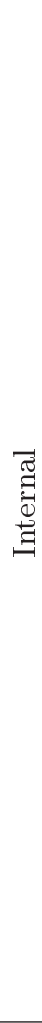 } & Accommodation support & Hinze et al. [34]; Srour et al. [28]. \\
\hline & Contract type & Drago and Wooden [50]; Cucchiella et al. [51]. \\
\hline & Job satisfaction & Drago and Wooden [50]; North et al. [52]. \\
\hline & Organizational policy & Hinze et al. [34]; North et al. [52]; Lusinyan and Bonato [24]; Srour et al. [28]. \\
\hline & Size of the working group & Hinze et al. [34]; Langenhoff [23]; Zhang et al. [47]; Grinza and Rycx [14]; \\
\hline & & Statistics Canada [26]. \\
\hline & Team work spirit & Hinze et al. [34]; Drago and Wooden [50]; Grinza and Rycx [14]. \\
\hline & Training & Lattouf et al. [45]; Srour et al. [28]. \\
\hline & Work pressure and overtime & TBR [7]; Langenhoff [23]; Loganathan and Kalidindi [31]. \\
\hline & Workers tenure & Drago and Wooden [50]; Srour et al. [28]; Grinza and Rycx [14]. \\
\hline & Alcohol & Bhosale and Biswas [30]; Loganathan and Kalidindi [31]. \\
\hline & $C$ ondor & Drago and Wooden [50]; North et al. [52]; Niedhammer et al. [53]; \\
\hline & 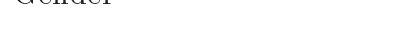 & Leaker [13]; Cucchiella et al. [51]. \\
\hline & Leisure time & Loganathan and Kalidindi [31]; Kerner et al. [54]. \\
\hline & Level of skill & North et al. [52]; Lattouf et al. [45]; Osorio-Sandoval et al. [43]. \\
\hline & & TBR [7]; North et al. [52]; Leaker [13]; Sichani et al. [11]; \\
\hline & Sickness & Lattouf et al. [45]; Bhosale and Biswas [30]; de Vroome et al. [44]; \\
\hline & & Loganathan and Kalidindi [31]. \\
\hline & Travel distance to the work & TBR [7]; Hinze et al. [34]; Sichani et al. [11]; Srour et al. [28]. \\
\hline \multirow{8}{*}{ 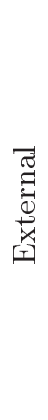 } & Salary level & Drago and Wooden [50]; Kim and Philips [55]. \\
\hline & Unemployment rate & North et al. [52]; Kim and Philips [55]. \\
\hline & Job safety & TBR [7]; North et al. [52]; Sichani et al. [11]; Biron and Bamberger [29]; \\
\hline & & Lattouf et al. [45]; Bhosale and Biswas [30]. \\
\hline & Weather condition & Rhodes and Steers [56]; Sichani et al. [11]; Lattouf et al. [45]; \\
\hline & & Loganathan and Kalidindi [31]. \\
\hline & Holidays & Lattouf et al. [45]; Bhosale and Biswas [30]; Loganathan and Kalidindi [31]. \\
\hline & Social norms & Ahn et al. [57]; Srour et al. [28]. \\
\hline
\end{tabular}

holidays, and reducing working hours. Loganathan and Kalidindi [31] studied migrant construction workers in India. Supporting workers with the on-site accommodation, sanitation facilities, daily meals, medical facilities, on-time payment, safety training, adequate materials and tools, and festivals and the harvest season vacations were among the strategies recommended by Loganathan and Kalidindi [31]. Srour et al. [28] studied absenteeism in Lebanon and recommended using small working groups and proper training for reducing the worker's absence rate.

A review of the past research indicates regional and cultural conditions as the main contributor to identifying the influential factors in and finding mitigation strategies for the worker's absence. For example, alcoholism has been identified as an influential factor in the worker's absence in India [30] and Hong Kong [32]. However, this factor may not be among the important factors here in Iran, given liquor trade is prohibited in the country. Therefore, an identical mitigation strategy cannot be globally prescribed for reducing the worker's absence rate. Instead, dedicated efforts are required for analyzing absenteeism in different regions. To fill a part of the existing gap for dedicated research on the worker's absence in Iran, this research aimed to identify the absence pattern and its main influential factors in the construction industry in Iran. The focus of this research was on internal influential factors.

\section{Methodology}

Direct data collection was adopted due to the lack of credible information on construction workers' absence in the country. Target statistical population was defined as laborers' supervisors, department managers, HR specialists (The HR specialists or Human Resource 
specialists refer to the construction company employees who work in the HR departments. The HR specialists are considered among the statistical population of the survey since they are normally involved in the process of accounting for the employees' compensable and noncompensable absence.), HR managers, and company Chief Executive Officers (CEOs).

Here, HR specialists represent the construction company employees who work at HR departments. The HR specialists are considered among the statistical population of the survey since they are normally involved in the process of accounting for the employees' compensable and non-compensable absence.

Working group supervisors and department managers were selected as the main parts of the target population due to their overall insights regarding the absence pattern of the workers working under their supervision. The exact size of the statistical population was unknown. However, according to the National Center of Iranian Construction Contractors (NCICC) [33] in 2018, approximately 25,000 active construction companies were registered with the NCICC. Considering multiple eligible respondents in each construction company, the population size of the statistical society easily goes beyond 100,000 . A questionnairebased survey method was adopted for data collection due to the large population of the statistical society. A questionnaire was designed to capture different aspects of the worker's absence pattern. A pilot survey was performed to test the validity of different questions and estimate the required sample size before the actual questionnaire distribution. The data collection was performed by randomly contacting construction companies from the list until the required number of valid questionnaires was returned. The collected data were then statistically analyzed to identify different aspects of the construction worker's absence pattern including the most important influential factors. Figure 1 presents the different stages of the conducted research.

\section{Questionnaire design}

The designed questionnaire contained 30 questions and was categorized into three main parts including:

1. The respondent's general information;

2. The worker's absence definition and frequency;

3. The absence pattern.

The third part of the questionnaire aimed to identify the main internal influential factors. The research team prepared a list of internal influential factors identified from different research attempts (Table 1) in designing this part of the questionnaire. Further explanation regarding the presented questions in three different parts of the questionnaire is given below.

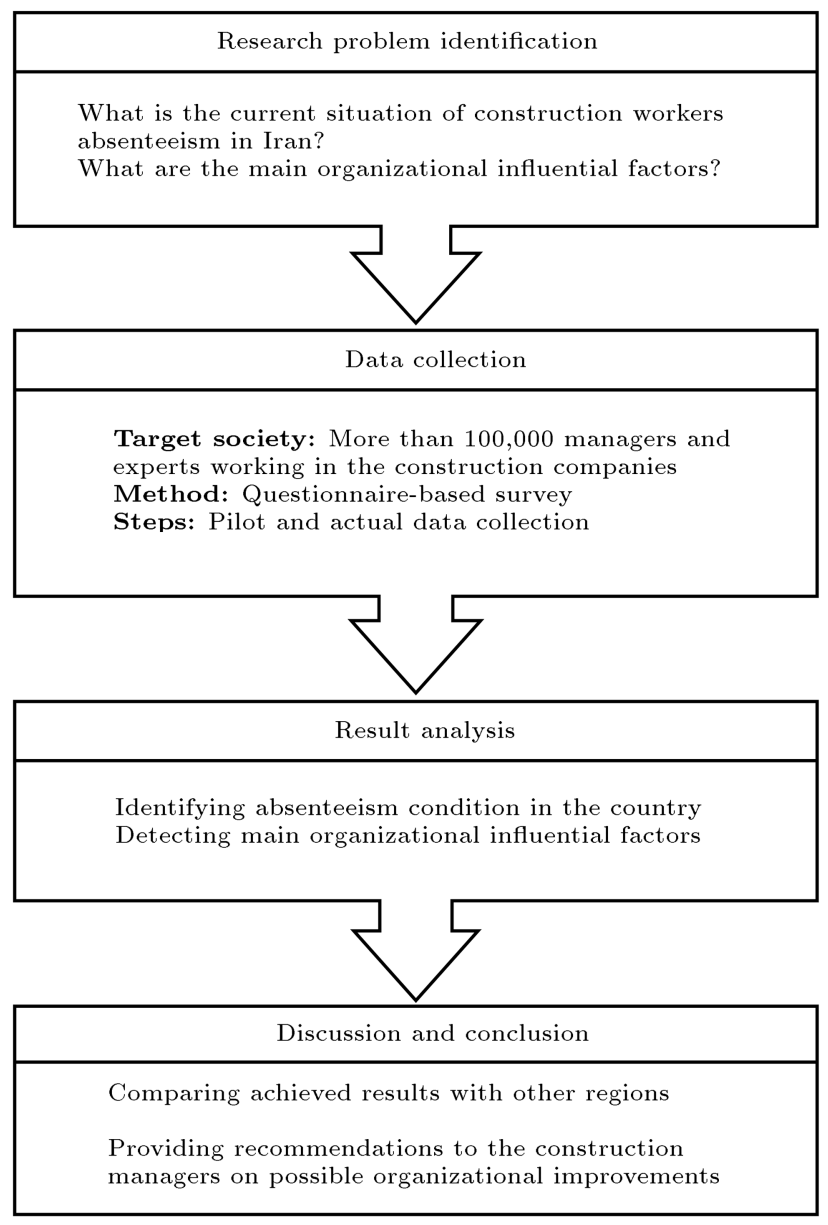

Figure 1. Different stages of the research.

\subsection{Part 1: General information}

In this part, four background questions were asked. These questions were designed to collect the respondent's job position, years of experience, experience in the current organization, and the size of the respondent's working group. These questions were outlined in the questionnaire's heading and were not numbered.

\subsection{Part 2: Absence definition and frequency}

The worker's absence during a working day has a wide range of several minutes to an entire day. Before collecting the respondents' responses to different questions about the worker's absence, their perceptions regarding an absent worker about the first question of this part were drawn. Here, respondents were asked to significantly determine the minimum hours of a worker's absence affecting the workers' performance during the day. In the second question, the minimum number of days of absence per month with a considerable impact on a worker's performance was asked. In the research, workers with the number of absent days per month equal to or higher than the minimum absent days per month were identified as frequent absentees. The next three questions in this part were used to collect the 
frequency of the worker's absence and absenteeism in the construction projects. Percentage of the frequent absentees, the average workers' absent days, and the frequency of the workers' absenteeism were asked in the next three questions of this part.

\subsection{Part 3: Absence pattern}

This part of the questionnaire was categorized into five different categories to capture the absence pattern in five various aspects. These aspects include:

1. In-advance notification;

2. Management policy;

3. Specific occasions;

4. Size of the working groups;

5. Worker's characteristics.

Further discussion about the designed questions in each category is given in the following:

1. In-advance notification: The unplanned cause of the worker's absence may occur several days before the absence day. Therefore, the absentees might have a short time to give an in-advance notice of the absence to the supervisor. This short notification from the absentee can provide a chance for mitigating the resulting disturbance and productivity loss [11]. Here, questions were asked about the possibility of in-advance notifications and their impacts on job productivity;

2. Management policy: Management policy was identified as an influential factor in the worker's absence rate [34]. Visiting job sites regularly [23], encouraging teamwork spirit, publicly announcing absentees [11], and enforcing serious implications for the absentees [34] were reported as some management policies. In the survey, respondents were asked to rank the impacts of different management policies on the worker's absence rate;

3. Specific occasions: The trend of the worker's absence is likely affected by specific occasions and seasons over the year. These occasions vary in different countries with different cultures and work environments. Here, respondents were asked to mark specific occasions with high absence rates over the year;

4. Size of the working groups: It is expected that a low level of supervision be applied to large working groups. Therefore, expectedly, the worker's absence rate is relatively high in large working groups. Identifying the impact of the working group sizes on the worker's absence can assist construction project managers to efficiently adjust the size of the working groups and the project organization. Here, a set of questions was designed to capture the impacts of the size of the working group on the worker's absence. Group supervisors were asked to indicate the average number of workers working under their supervision. They were also asked to determine the average absence rate of their working groups. Further, they were directly asked to rank the impacts of the working group size on the worker's absence. The last question in this part was meant to represent a relatively similar response implied from the first two questions. This question was used for testing the validity of the respondents' answers;

5. Workers' characteristics: Workers with specific traits may frequently become absent as a result of the issues they struggle with. Identifying these characteristics helps construction project managers focus on the source of the problems and plan for addressing them effectively. Therefore, in this part, the respondents of the questionnaire were asked if they could name specific characteristics of the frequent absentees.

\section{Pilot study}

This pilot study constituted 20 participating respondents. The validity of the questions was tested in consultation with the pilot group. Several questions were revised according to the feedback received from the experts who participated in the pilot study. The minimum number of samples was also estimated according to the Cochran [35] sample size equation. The minimum adequate sample size was estimated at 124 with a maximum standard deviation of 1.13 for questions, a confidence interval of $95 \%$, and an acceptable error level of 0.2 .

\section{Data collection}

A total number of 150 questionnaires were distributed and 127 responses were returned. The Cronbach's alpha [36-42] is a commonly used reliability test for verifying the consistency of the collected data. IBM SPSS statistics software was employed for testing the reliability of the collected data using Cronbach's alpha and intra-class correlation tests. The standardized items including Cronbach's alpha of 0.722 and the average intra-class correlation of 0.708 confirmed the reliability of the collected data.

According to the collected data, $60 \%$ of the respondents were working in the construction sites and $40 \%$ were in the office. Approximately $26 \%$ of the respondents were directly in charge of small working groups with less than five members. Besides, $31 \%$ of them were in charge of working groups of 5 to 10 members, and $37 \%$ were in charge of large working groups with more than 10 members. Approximately, 


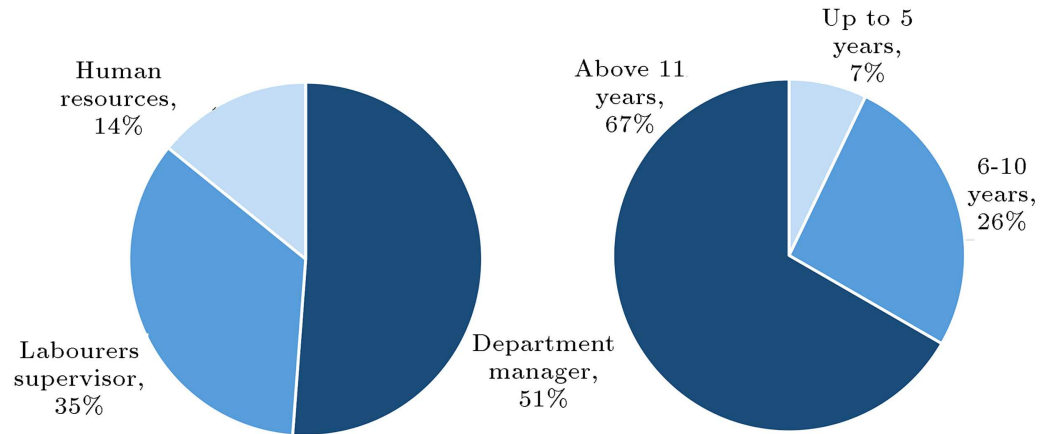

(a) Job position

(b) Overall work experience

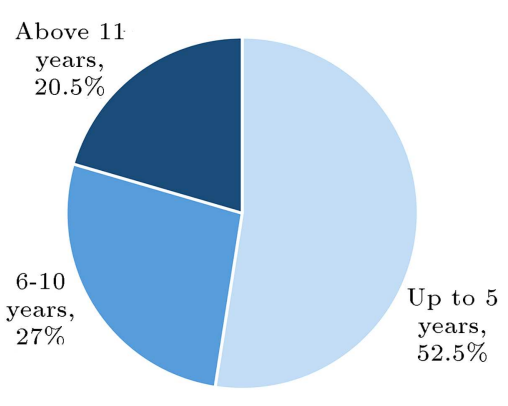

(c) Experience in the current company

Figure 2. Distribution of the respondents in different aspects.

Table 2. Absence pattern in construction projects in Iran.

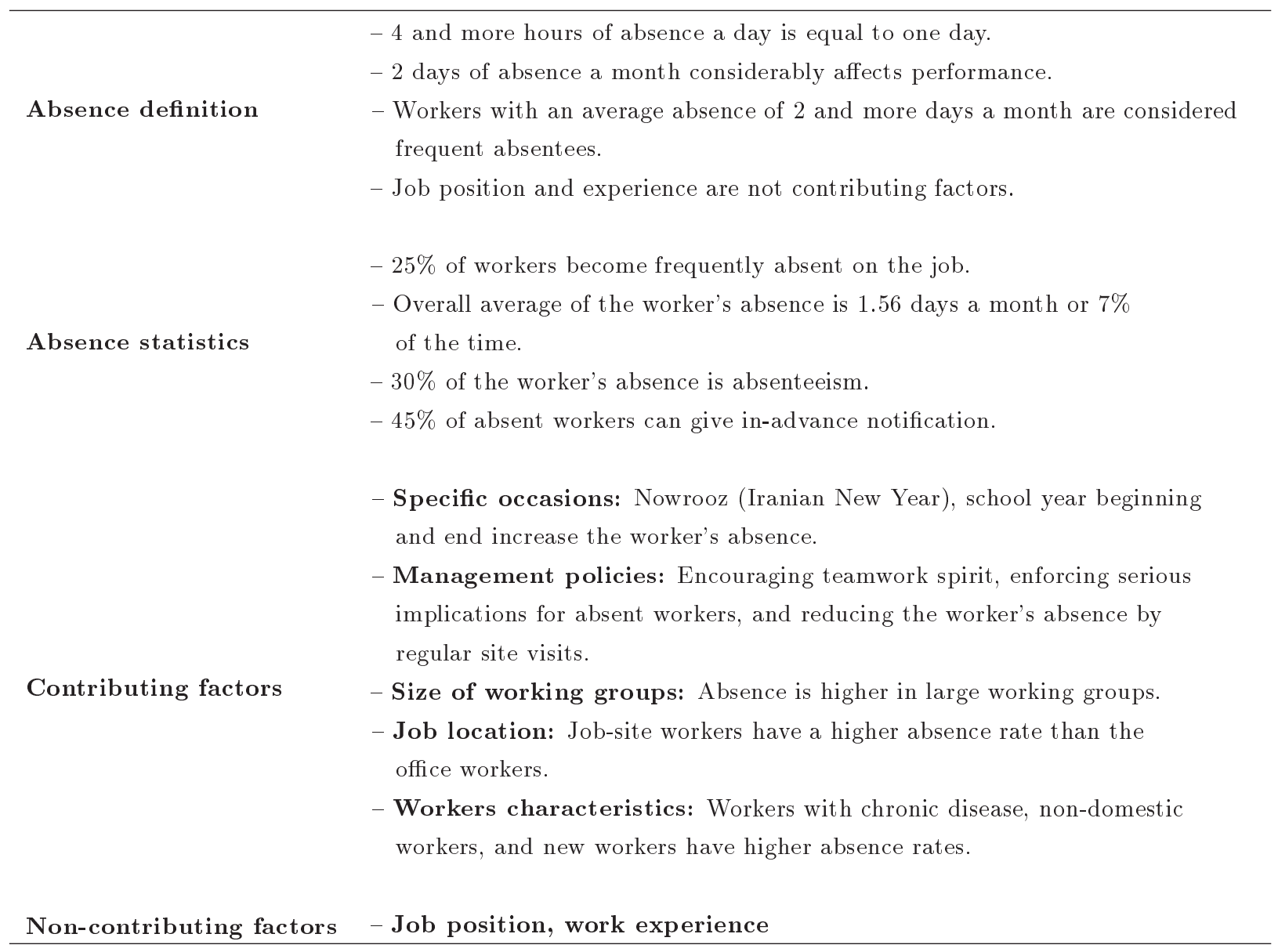

$6 \%$ of the respondents were HR specialists who were not in charge of any working groups. Department managers with $51 \%$ frequency comprised the highest portion of the respondents. They were followed by laborer supervisors with $35 \%$ and HR staff including HR managers and HR specialists with $14 \%$. Approximately, $67 \%$ of the respondents had a general work experience for more than 11 years. The majority of the respondents with a frequency of $52.5 \%$ had up to
5 years of work experience in their current company. Figure 2 represents the distribution of the respondents in different aspects.

\section{Absence pattern}

Achieved results revealed different aspects of the absence pattern in the construction industry in Iran. Table 2 summarizes the worker's absence pattern in 
the construction projects in Iran. Further explanation about the achieved results is provided in the rest of the section.

\subsection{Definition of the absent worker}

Almost $70 \%$ of the respondents pointed out that up to four hours of the worker's absence per day ruins the entire day's performance. In this situation, workers can be deemed absent for the entire day. Almost $51 \%$ of the respondents expressed that a minimum of two days of the worker's absence in a month had a considerable impact on the worker's performance. Therefore, workers with an average absence rate for more than two days a month were considered frequent absentees. The one-way ANOVA (analysis of variance) test with a significance level of 0.05 was conducted on the collected data for the impacts of job position and work experience on evaluating the worker's absence rate using IBM SPSS statistics software. Job position and work experience were selected as independent factors, and the evaluation of workers' absence rate was set as the dependent variable. Table 3 represents the result achieved for the impact of job position, and Table 4 represents the result achieved for the impact of work experience on the worker's absence rate evaluation. In both cases, the achieved statistical significance values represent higher values than a significance level of 0.05 set for the ANOVA. Therefore, neither job position nor work experience could be identified as a contributing factor in the worker's absence rate.

\subsection{Absence rate}

On average, respondents identified that $25 \%$ of workers were frequent absentees. The overall average worker's absence rate reached 1.56 days a month or approximately $7 \%$ of the working time. Almost, $55 \%$ of the respondents estimated the average worker's absence rate in their company equal to or more than two days a month. Finally, the respondents indicated that on average, about $30 \%$ of the worker's absence resulted from inexcusable reasons, i.e., absenteeism. Figure 3 compares the worker's absence rate reported in the

Table 3. One-way ANOVA test conducted in IBM SPSS for the impact of job position on the workers absence rate evaluation.

\begin{tabular}{lccccc}
\hline & $\begin{array}{c}\text { Sum of } \\
\text { squares }\end{array}$ & $\begin{array}{c}\text { Degrees of } \\
\text { freedom }\end{array}$ & $\begin{array}{c}\text { Mean } \\
\text { square }\end{array}$ & F-statistics & $\begin{array}{c}\text { Statistical } \\
\text { significance }\end{array}$ \\
\hline Between groups & 1.033 & 3 & 0.344 & 0.520 & 0.670 \\
Within groups & 76.834 & 116 & 0.662 & & \\
Total & 77.867 & 119 & & & \\
\hline
\end{tabular}

Table 4. One-way ANOVA test conducted in IBM SPSS for the impact of work experience on the workers absence rate evaluation.

\begin{tabular}{lccccc}
\hline & $\begin{array}{c}\text { Sum of } \\
\text { squares }\end{array}$ & $\begin{array}{c}\text { Degrees of } \\
\text { freedom }\end{array}$ & $\begin{array}{c}\text { Mean } \\
\text { square }\end{array}$ & F-statistics & $\begin{array}{c}\text { Statistical } \\
\text { significance }\end{array}$ \\
\hline Between groups & 2.733 & 3 & 0.911 & 1.407 & 0.244 \\
Within groups & 75.133 & 116 & 0.648 & & \\
Total & 77.867 & 119 & & & \\
\hline
\end{tabular}

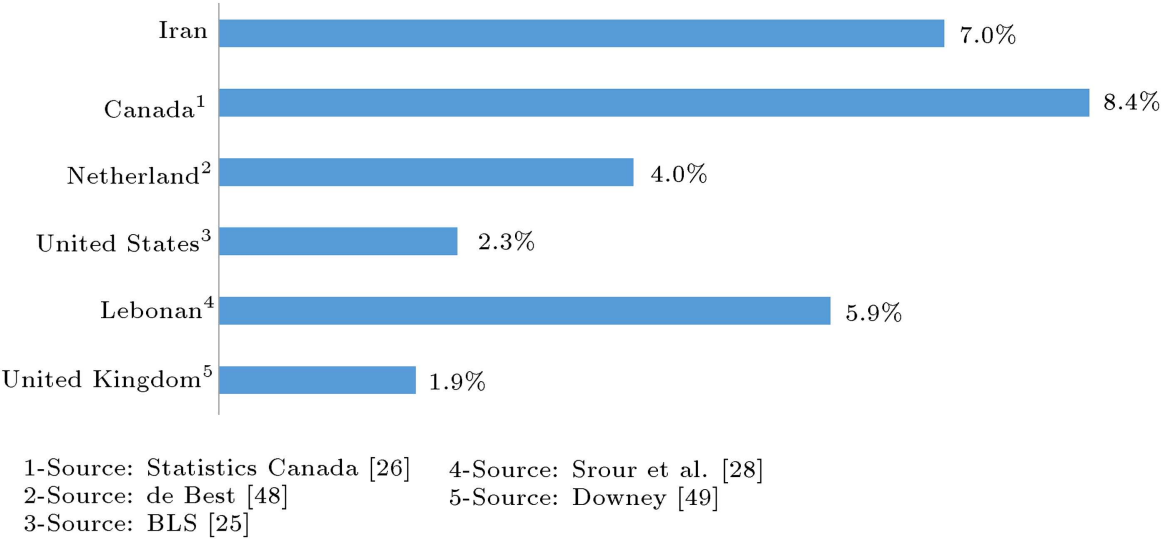

Figure 3. The worker's absence rate in the construction industry in different countries. 
literature for the construction industry in different countries. The average absence rate of $7 \%$ in Iran represents the second-highest rate after Canada with an absence rate of $8.4 \%$.

\subsection{In-advance notification}

Approximately, $95 \%$ of the respondents believed that in-advance absence notification could highly or fairly reduce the negative impacts of the worker's absence. Meanwhile, it was estimated that, on average, $45 \%$ of the absent workers could give an in-advance notification for at least one day before their absence. About $87 \%$ of respondents expressed that the top management support for in-advance notification could highly or fairly increase the number of in-advance notifications.

\subsection{Management policies}

Approximately $84 \%$ of respondents believed that proper management and organizational policy could have a high or fair impact on reducing the worker's absence rate. Figure 4 presents the impacts of four different management policies on the worker's absence evaluated in the survey. Three of the policies were identified with high or fair impacts on the worker's absence rate by more than $90 \%$ of the respondents. These management policies include: 1) encouraging teamwork spirit, 2) enforcing serious implications for absent workers, and 3) visiting the job-sites regularly. The fourth policy, i.e., publically announcing workers' days of absence, however, received a narrow majority

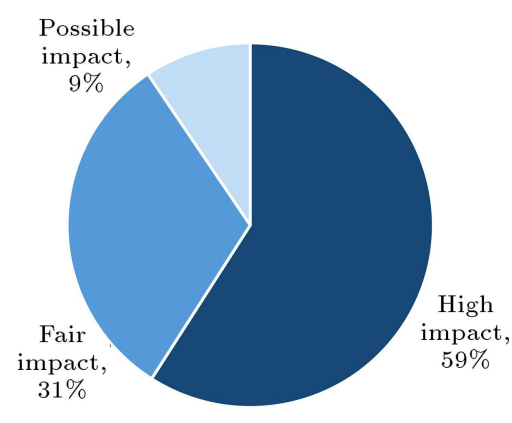

(a) Encouraging team work

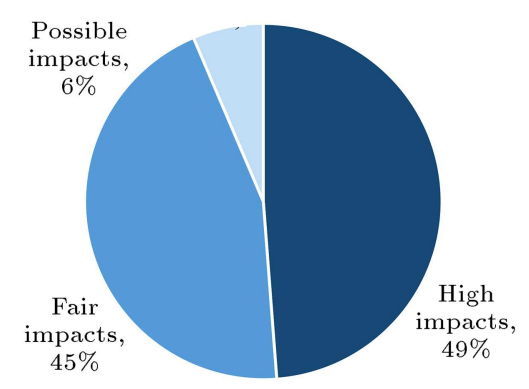

(c) Regular on site visits of $53 \%$. Meanwhile, only $20 \%$ of respondents identified currently enforced worker's absence policies to be fairly or quite suitable.

\subsection{Specific occasions}

About $47 \%$ and $33 \%$ of the respondents identified the first and last months of the Persian calendar as the occasions with high worker's absence rates, respectively. Around $10 \%$ of the respondents mentioned the beginning of the school year, while $7 \%$ of them identified the end of the school year as occasions with high absence rates. In total, $87 \%$ of the respondents believed that work productivity was highly or fairly reduced during these special occasions.

\subsection{Size of the working groups}

Around $81.5 \%$ of the respondents indicated that the absence rate was higher in the large working groups than the small working groups. Almost $83 \%$ of the respondents indicated that breaking large working groups into several small groups could reduce the worker's absence rate. As presented in Figure 5, the worker's absence ranges from 0.98 days a month in small working groups of up to five members to 1.89 days a month in large groups with more than ten members. Achieved results illustrate that the size of the working groups linearly relates to the number of the worker's absence rate. One-way ANOVA test was performed with a significance level of 0.05 for testing the relation between working group size, as an independent factor, and the working group absence rate, as a dependent variable.

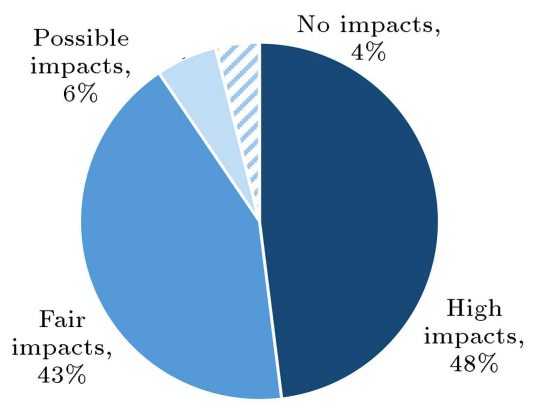

(b) Enforcing serious implications

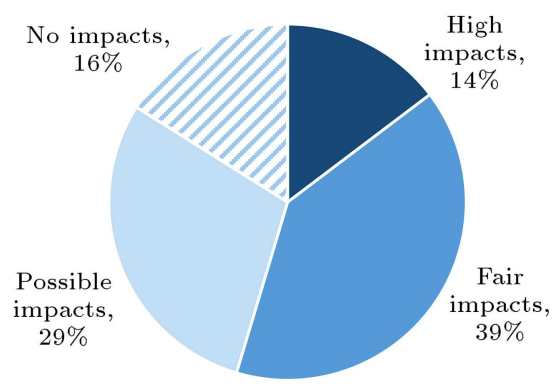

(d) Posting workers' absent days

Figure 4. Impacts of different management policies on the worker's absence. 
Table 5. One-way ANOVA test conducted for the impact of the group size on the workers absence rate evaluation.

\begin{tabular}{lccccc}
\hline & $\begin{array}{c}\text { Sum of } \\
\text { squares }\end{array}$ & $\begin{array}{c}\text { Degrees of } \\
\text { freedom }\end{array}$ & $\begin{array}{c}\text { Mean } \\
\text { square }\end{array}$ & F-statistics & $\begin{array}{c}\text { Statistical } \\
\text { significance }\end{array}$ \\
\hline Between groups & 19.377 & 3 & 6.459 & 12.176 & 0.000 \\
Within groups & 55.169 & 104 & 0.530 & & \\
Total & 74.546 & 107 & & & \\
\hline
\end{tabular}

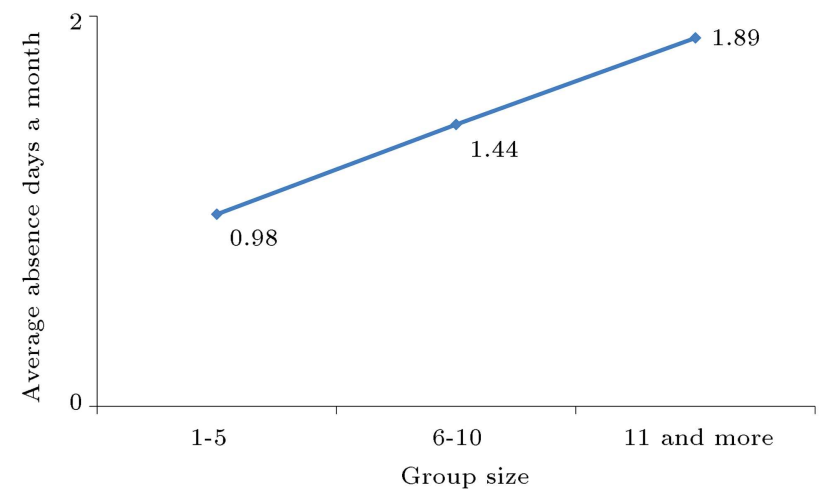

Figure 5. Average absence days in working groups with different sizes.

The statistical significance value of zero achieved in the test (the last column in Table 5) confirmed this relation.

\subsection{Workers' characteristics}

Workers with a chronic disease with a frequency of $42 \%$, non-domestic workers with a frequency of $26 \%$, and new or rooky workers with a frequency of $23 \%$ represented the highest absence rates among different groups of the workers, respectively. The results of identifying sickness absence as the most important personal reason for the worker's absence are consistent with the results reported in the past research (e.g. [30,31,43,44]). The job location was also identified as a contributing factor in the worker's absence rate in the construction projects. The achieved significance value of 0.001 in the conducted one-way ANOVA test affirmed the worker's job location, i.e., office or job-site, as a contributing factor in the absence rate (Table 6). The average absence rate was achieved 1.27 days a month for the office workers and 1.79 days a month for the on-site workers.

\section{Discussion and analysis}

Part of the reduced performance in the construction projects in Iran lies in the high rate of absence compared to other countries. It was identified that the current organizational policies fell short of properly addressing the worker's absence. Nearly $30 \%$ of the worker's absence resulted from inexcusable reasons which could be reduced by proper organizational policies. Enhancing teamwork spirit among the workers, enforcing serious implications for inexcusable absence, and setting regular site visits by managers are among the policies found useful. The main portion of the high absence rate in the construction projects was directed to $25 \%$ of the frequent absentees. Close to $70 \%$ of the worker's absence resulted from excusable reasons such as chronic disease, overwhelming issues in the new society far from the homeland, or being swamped in the new work environment. Therefore, construction project managers are recommended to pay attention to the specific condition of these groups of workers. It is expected that the increased organizational sensitivity and support for the excusable worker's absence can result in the reduced worker's absence rate. Providing complementary medical and accommodation benefits and holding proper orientation and mentoring programs are the options required for reducing excusable worker's absence.

The absence rate was found higher for on-site workers than office workers. Harsh weather conditions and high work pressure are the two elements of the construction job-sites that have been previously reported as influential factors in the worker's absence in the literature (e.g. $[11,31,45])$. These two factors might have played roles in increasing the worker's absence here as well. The project managers are recommended to pay particular attention to on-site

Table 6. One-way ANOVA test conducted for the impact of the working location on the working group absence rate evaluation.

\begin{tabular}{lccccc}
\hline & $\begin{array}{c}\text { Sum of } \\
\text { squares }\end{array}$ & $\begin{array}{c}\text { Degrees of } \\
\text { freedom }\end{array}$ & $\begin{array}{c}\text { Mean } \\
\text { square }\end{array}$ & F-statistics & $\begin{array}{c}\text { Statistical } \\
\text { significance }\end{array}$ \\
\hline Between groups & 7.359 & 1 & 7.359 & 11.610 & 0.001 \\
Within groups & 67.188 & 106 & 0.634 & & \\
Total & 74.546 & 107 & & & \\
\hline
\end{tabular}


policies and supports. However, it should be noted that both excessive pressure and extra encouragement for the worker's attendance can result in the workers' presenteeism. Presenteeism or attending the job with improper conditions such as sickness or anxiety can reversely result in reduced performance [46].

Many project managers are reluctant to increase the number of highly paid work supervisors who are in charge of supporting tasks that do not directly contribute to the project progress. This tendency, however, can ultimately result in forming large working groups in the construction projects. According to the results achieved in this study, large working groups have higher absence rates than small groups. The identified relationship between the size of the working groups and the worker's absence rate was also pointed out in the past research (e.g. $[14,23,26,34,47])$. It should be noted that the reduced worker's absence and its consequent performance increase can justify additional payments to the work supervisors in many cases.

\section{Summary and conclusion}

This research remains the first investigation conducted to explore the worker's absence pattern in the specific condition of construction projects in Iran. The overall perspective of the construction worker's absence pattern was drawn in the country, and the country's standing was compared with several other countries. Unlike many other performance indicators, calculation of the worker's absence rate and its other related indicators in an organization is relatively simple only by using the worker's payroll. Therefore, the identified absence pattern in this investigation can be used by construction managers to compare their organizations' standings. Provided recommendations can be used for them to adjust their organizational policies. Investigating impacts of these recommendations on the worker's absence in real cases, however, can be followed in future research. The focus of the conducted investigations was on the intra-organizational and personal aspects of the worker's absence in the construction projects. External influential factors can also affect the worker's absence rate in the construction projects, which were not investigated here. New research efforts are encouraged to examine these factors. In particular, Iran's labor law is quite notorious among the construction project contractors to be one-sided in favor of workers. New investigations into the possible impacts of the current labor law on the worker's absence can clarify the fact.

\section{References}

1. Gundecha, M.M., Study of Factors Affecting Labour Productivity at a Building Construction Project in the USA, Web survey, pp. 1-76 (Sept. 2012).
2. Gerges, M., Ahiakwo, O., Aziz, R., Kapogiannis, G., Saidani, M., and Saraireh, D. "Investigating and ranking labor factors productivity in Egyptian construction industry", Int. J. Archit. Eng. Constr., 5(1), pp. 44-52 (2016).

3. Omar, M.N. and Fayek, A.R. "A framework for identifying, monitoring, and controlling construction workforce absenteeism using the absenteeism tracking tool", Int. J. Archit. Eng. Constr., 1(4), pp. 231-242 (2012).

4. Gopal, T.G.S.R. and Murali, K. "Secondary data analysis on factors affecting labour productivity in construction", Int. J. Sci. Res. Publ., 6(5), pp. 401405 (2016).

5. Agrawal, A. and Halder, S. "Identifying factors affecting construction labour productivity in India and measures to improve productivity", Asian J. Civ. Eng., 21(4), pp. 569-579 (2020).

6. Doyle, C. and Cicchetti, D. "From the cradle to the grave: The effect of adverse caregiving environments on attachment and relationships throughout the lifespan", Clin. Psychol. Sci. Pract., 24(2), pp. 203-217 (2017).

7. TBR, Absenteeism and Turnover (1982).

8. Ferguson, T.D., Ferguson, W.L., Muedder, K., and Fitzgerald, M.P. "The case for total absence management and integrated benefits", Hum. Resour. Plan., 24(3), pp. 36-46 (2001).

9. Hanna, A.S., Menches, C.L., Sullivan, K.T., and Sargent, J.R. "Factors affecting absenteeism in electrical construction", J. Constr. Eng. Manag., 131(11), pp. 1212-1218 (2005).

10. Nicholson, S., Pauly, M.V., Polsky, D., Sharda, C., Szrek, H., and Berger, M.L. "Measuring the effects of work loss on productivity with team production", Health Econ., 15(2), pp. 111-123 (2006).

11. Sichani, M.S., Lee, S.H., and Fayek, A.R. "Understanding construction workforce absenteeism in industrial construction", Can. J. Civ. Eng., 38(8), pp. 849858 (2011).

12. Strömberg, C., Aboagye, E., Hagberg, J., Bergström, G., and Lohela-Karlsson, M. "Estimating the effect and economic impact of absenteeism, presenteeism, and work environment-related problems on reductions in productivity from a managerial perspective", Value Heal., 20(8), pp. 1058-1064 (2017).

13. Leaker, D. "Sickness absence from work in the UK", Econ. Labour Mark. Rev., 2(11), pp. 18-22 (2008).

14. Grinza, E. and Rycx, F. "The impact of sickness absenteeism on firm productivity: New evidence from Belgian matched employer-employee panel data", Ind. Relat., 59(1), pp. 150-194 (2020).

15. ProjectIran, Meet the Promise of the Rising Iranian Market (2017).

16. Rafieizonooz, M., Salim, M.R., Khankhaje, E., Warid Hussin, M., Zarebidaki, A., and Salmiati, S. "Determining the causes of delay by using factor analysis in 
Tehran's construction projects", Appl. Mech. Mater., 735, pp. 109-116 (2015).

17. Samarghandi, H., Tabatabaei, S.M.M., Taabayan, P., Hashemi, A.M., and Willoughby, K. "Studying the reasons for delay and cost overrun in construction projects: The case of Iran", J. Constr. Dev. Ctries., 21(1), pp. 51-84 (2016).

18. Derakhshanalavijeh, R. and Teixeira, J.M.C. "Cost overrun in construction projects in developing countries, Gas-Oil industry of Iran as a case study", J. Civ. Eng. Manag., 23(1), pp. 125-136 (2017).

19. Alvanchi, A., Farmani, N., and Haji Yakhchali, S. "Evaluating factors causing delay in residential building projects of Mashhad", Sharif J. Civ. Eng., 35.2(3.2), pp. 3-13 (2019).

20. Khanzadi, M., Kaveh, A., Alipour, M., and Mohammadi, R.K. "Assessment of labor productivity in construction projects using system dynamic approach", Sci. Iran., 24(6), pp. 2684-2695 (2017).

21. Moradi, S., Nasirzadeh, F., and Golkhoo, F. "Modeling labor productivity in construction projects using hybrid SD-DES approach", Sci. Iran., 24(6), pp. 27522761 (2017).

22. Golchin Rad, K. and Kim, S.Y. "Factors affecting construction labor productivity: Iran case study", Iran. J. Sci. Technol., Trans. Civ. Eng., 42(2), pp. 165-180 (2018).

23. Langenhoff, W. "Employee absenteeism: Construction of a model for international comparison of influential determinants", Erasmus University Rotterdam, Erasmus School of Economics, Master Thesis, p. 79 (2011).

24. Lusinyan, L. and Bonato, L. "Work absence in Europe", IMF Staff Pap., 54(3), pp. 475-538 (2007).

25. U.S. Bureau of Labor Statistics, Absences from Work of Employed Full-Time Wage and Salary Workers by Occupation and Industry, U.S. Bureau of Labor Statistics, Division of Labor Force Statistics (2020).

26. Statistics Canada, Labour Force Survey Estimates (LFS), Work Absence Statistics of Full-Time Employees by Sex and Establishment Size Annual (2018).

27. CIPD, Absence Management - Annual Survey Report (2016).

28. Srour, F.J., Srour, I., and Lattouf, M.G. "A survey of absenteeism on construction sites", Int. J. Manpow., 38(4), pp. 533-547 (2017).

29. Biron, M. and Bamberger, P. "Aversive workplace conditions and absenteeism: taking referent group norms and supervisor support into account", J. Appl. Psychol., 97(4), pp. 901-912 (2012).

30. Bhosale, C.D. and Biswas, A. "Absenteeism in construction industry: Causes, correlation and remedies", Int. J. Adv. Eng. Res. Technol., 3(6), pp. 215-218 (2015).

31. Loganathan, S. and Kalidindi, S.K. "Absenteeism and turnover of migrant construction workers in Indian projects-Survey-based study", Proc. Constr. Res. Congr., 2016, pp. 2039-2049 (2016).
32. Rowlinson, S., Shen, Y., and Koh, T.Y. "Alcohol consumption patterns of construction workers in Hong Kong", 6th World Constr. Symp., pp. 27-32 (2017).

33. NCICC, "NCICC history", http://abadgar.org/.

34. Hinze, J., Ugwu, M., and Hubbard, L. "Absenteeism in construction industry", J. Manag. Eng., 1(4), pp. 188-200 (1985).

35. Cochran, W.G., Sampling Techniques, 3rd Edn., New York: John Wiley \& Sons (1977).

36. Santos, J.R.A. "Cronbach's alpha: A tool for assessing the reliability of scales", J. Ext., 37(2), pp. 88-92 (1999).

37. Gliem, J.A. and Gliem, R. "Calculating, interpreting, and reporting cronbach's alpha reliability coefficient for likert-type scales", 2003 Midwest Res. to Pract. Conf. Adult, Contin. Community Educ. Calc., pp. 8288 (2003).

38. Tavakol, M. and Dennick, R. "Making sense of Cronbach's alpha", Int. J. Med. Educ., 2, pp. 53-55 (2011).

39. Bohannon, R.W. and Smith, M.B. "Interrater reliability of a modified Ashworth scale of muscle spasticity", Phys. Ther., 67(2), pp. 206-207 (1987).

40. Rust, R. and Grayson, K. "Reliability assessment reliability assessment interrater reliability", 10, pp. 71-73 (2001).

41. Grayson, K. "Interrater reliability", J. Consum. Psychol., 10(1), pp. 71-73 (2001).

42. Jette, D.U., Stilphen, M., Ranganathan, V.K., Passek, S., Frost, F.S., and Jette, A.M. "Interrater reliability of AM-PAC '6-Clicks' basic mobility and daily activity short forms", Phys. Ther., 95(5), pp. 758-766 (2015).

43. Osorio-Sandoval, A.C., Corona-suárez, G.A., Osoriosandoval, C.A., Zaragoza-grifé, J.N., Corona-, G.A., and González-fajardo, J.A. "Discrete event simulation analysis of the effect of labor absenteeism on the duration of construction activities in housing projects", Int. J. Eng. Res. Appl., 6, pp. 46-55 (Dec., 2016).

44. de Vroome, E.M., Uegaki, K., van der Ploeg, C.P. Treutlein, D.B., Steenbeek, R., de Weerd, M., and van den Bossche, S.N. "Burden of sickness absence due to chronic disease in the Dutch workforce from 2007 to 2011", J. Occup. Rehabil., 25(4), pp. 675-684 (2015).

45. Lattouf, M.G., Srour, F.J., and Srour, I.M. "Construction workforce management strategies to reduce absenteeism: A survey study", Constr. Res. Congr. 2014 Constr. a Glob. Netw., pp. 827-836 (2014).

46. Lohaus, D. and Habermann, W. "Presenteeism: A review and research directions", Hum. Resour. Manag. Rev., 29(1), pp. 43-58 (2019).

47. Zhang, W., Sun, H., Woodcock, S., and Anis, A.H. "Valuing productivity loss due to absenteeism: firmlevel evidence from a Canadian linked employeremployee survey", Health Econ. Rev., 7(1), pp. 1-14 (2017). 
48. Statista "Sickness absence rate in the Netherlands 2001-2019", Statista Research Department, Hamburg, Germany, www.statista.com (2020).

49. Downey, K. "UK sickness absence rate reaches alltime low", Iosh Magazine, Institution of Occupational Safety and Health, UK, Published online on 3rd August 2018 (2018).

50. Drago, R. and Wooden, M., "The determinants of labor absence: Economic factors and workgroup norms across countries", Ind. Labor Relations Rev., 45(4), pp. 764-778 (1992).

51. Cucchiella, F., Gastaldi, M., and Ranieri, L. "Managing absenteeism in the workplace: The case of an Italian multiutility company", Procedia - Soc. Behav. Sci., 150, pp. 1157-1166 (2014).

52. North, F., Syme, S.L., Feeney, A., Head, J., Shipley, M.J., and Marmot, M.G. "Explaining socioeconomic differences in sickness absence: The Whitehall II study", Br. Med. J., 306(6874), pp. 361-366 (1993).

53. Niedhammer, I., Goldberg, M., Leclerc, A., Bugel, I., and David, S. "Psychosocial factors at work and subsequent depressive symptoms in the Gazel cohort", Scand. J. Work. Environ. Heal., 24(3), pp. 197-205 (1998).

54. Kerner, I., Rakovac, M., and Lazinica, B. "Leisuretime physical activity and absenteeism", Arh. Hig. Rada Toksikol., 68(3), pp. 159-170 (2017).

55. Kim, J. and Philips, P. "Remuneration and absen- teeism on a large construction site", Constr. Manag. Econ., 32(10), pp. 983-999 (2014).

56. Rhodes, S. and Steers, R. "A systematic approach to diagnosing employee absenteeism", Empl. Relations, 3(2), pp. 17-22 (1981).

57. Ahn, S., Lee, S., and Steel, R.P. "Effects of workers' social learning: Focusing on absence behavior", $J$. Constr. Eng. Manag., 139(8), pp. 1015-1025 (2013).

\section{Biographies}

Amin Alvanchi is an Assistant Professor at the Department of Civil Engineering specializing in construction en gineering and management at Sharif University of Technology, Tehran, Iran since February 2013. He received his $\mathrm{PhD}$ in Construction Engineering and Management from the University of Alberta, Canada in 2011. His area of research focuses on construction project management, building information modeling, construction operation simulation, and contract administration.

Amirhosein Hashemi is an MSc student in the Construction Engineering and Management program of the Department of Civil Engineering, Sharif University of Technology, Tehran, Iran. His research and work focus is on project management and building information modeling. 